\title{
Vitamins $A$ and $E$ in the maternal diet influence egg quality and early life stage development in fish: a review
}

\author{
VINCE P. PALACE ${ }^{1}$ and JULIETA WERNER ${ }^{2}$ \\ ${ }^{1}$ Department of Fisheries and Oceans, Winnipeg, Canada. E-mail: palacev@dfo-mpo.gc.ca \\ ${ }^{2}$ University of Manitoba, Department of Zoology, Winnipeg, Canada.
}

\begin{abstract}
SUMMARY: Early development in fish is dependent on essential nutrients present in the egg. Vitamins E and A are critical to the normal development of fish embryos. Vitamin E functions primarily as an antioxidant to protect unsaturated lipids from oxidative degradation. Vitamin A or its provitamin carotenoid forms support growth, are required for the differentiation and maintenance of epithelial tissue and can be converted to forms of the vitamin that are potent morphogens. Fish cannot synthesise either of the vitamins, so the maternal dietary content of each prior to oogenesis is an important determinant of reproductive fitness. Here we review the basic metabolism of vitamins E and A and carotenoids and their processing from the maternal diet and deposition into eggs. Evidence for the link between levels of each of the vitamins in eggs and measures of reproductive fitness are also discussed.
\end{abstract}

Keywords: vitamins, tocopherol, retinol, carotenoids, fish eggs, reproductive fitness.

RESUMEN: VITAMINAS A Y E EN LA DIETA MATERNAL Y SU INFLUENCIA EN LA CALIDAD DEL HUEVO Y EL DESARROLLO EMBRIONARIO EN PECES: UNA REVISIÓN. - El desarrollo embrionario en peces es dependiente de los nutrientes esenciales presentes en el huevo. Las vitaminas E y A son críticas en el desarrollo normal de los embriones de los peces. La vitamina E funciona sobre todo como un antioxidante para proteger los lípidos no saturados contra la degradación oxidativa. La vitamina A, o los carotenoides formas de provitamina, se requieren para la diferenciación y el mantenimiento del tejido fino epitelial y se puede convertir a las formas de la vitamina que son morfogenes potentes. Los peces tampoco pueden sintetizar las vitaminas, de modo que el contenido dietético materno de cada una antes de la oogenesis es un determinante importante de la aptitud reproductiva. Aquí repasamos el metabolismo básico de las vitaminas E y A y los carotenoides y su procesamiento desde la dieta materna a la deposición en los huevos. Se discute también la evidencia del acoplamiento entre los niveles de cada una de las vitaminas en los huevos y las medidas de aptitud reproductiva en los adultos.

Palabras clave: vitaminas, tocoferol, retinol, carotenoides, huevos de peces, aptitud reproductiva.

\section{INTRODUCTION}

Early development in larval fish is dependent on the internal complement of essential nutrients that are present in the egg. These nutrients are, in turn, determined by the maternal diet prior to and during oogenesis (Laevens et al., 1999). Within the larger context of essential nutrients, dietary fatty acids are one of the strongest determinants of reproductive performance, with enhanced reproductive fitness being achieved by increasing dietary lipids (Izquierdo et al., 2001). Fish eggs are known to contain relatively high concentrations of a particular class of lipids, polyunsaturated fatty acid lipids (PUFA). PUFA are essential to normal development of fish and are incorporated into cellular and subcellular membranes, helping to maintain the fluidity of those membranes. Fluidity of membranes is espe- 
cially critical at low temperatures, including those at which some fish eggs typically develop (e.g. $4-5^{\circ} \mathrm{C}$ ) (Cowey et al., 1985). While imparting fluidity is essential, the structure of PUFA lipids makes them particularly susceptible to attack from reactive oxygen species (ROS).

ROS are natural byproducts of aerobic metabolism. Aerobic metabolism converts oxygen to water by the addition of four electrons with an efficiency of 95-99\% (Halliwell, 1987). A small percentage of the time, oxygen is only partially reduced (i.e. addition of only 1, 2 or 3 electrons) forming reactive oxygen species (ROS), including superoxide and the hydroxyl radical as well as hydrogen peroxide. ROS are highly reactive oxidants and can initiate lipid peroxidation, a chain reaction process that can damage PUFA lipids. Lipid peroxidation produces damaging lipid by-products including fatty acid hydroperoxides, aldehydes and hydrocarbons. These by-products can damage cell membranes, inactivate enzymes and damage macromolecules including DNA and RNA within the developing embryo (Mourente et al., 1999).

To allow vertebrates to cope with the continuous generation of ROS from normal aerobic metabolism, cells and tissues contain a series of enzymatic and non-enzymatic cellular antioxidants. Enzymes such as catalase, glutathione peroxidase, glutathione reductase and superoxide dismutase, and non-enzymatic factors such as vitamins $\mathrm{A}, \mathrm{C}$ and $\mathrm{E}$, glutathione, ubiquinone, iron chelators and thiol-containing proteins all function to neutralise ROS or byproducts within the cell (Halliwell and Gutteridge, 1990). As long as the cell, tissue, and whole organism can maintain antioxidant concentrations above the level of ROS generation, cellular components are protected.

ROS are constitutively produced during basal metabolism, but there are several situations in which their production is enhanced, including during exercise, with exposure to UV light, in cold temperatures, following ischemia reperfusion, with exposure to some contaminants and in organisms with a bacterial or fungal infection (Aruoma et al., 1991). Higher aerobic metabolism and generation of ROS also occurs during rapid tissue growth. Therefore, the early development stages of fish would be expected to increase the production of ROS. The antioxidant enzyme systems that are present in the liver and other tissues of adult fish are not synthesised until late in the embryonic development of lar- val fish. This makes early antioxidant protection by maternally derived non-enzymatic antioxidants essential (Cowey et al., 1985; Ciarcia et al., 2000).

The primary non-enzymatic antioxidants in fish eggs are vitamins $\mathrm{E}$ and $\mathrm{A}$ as well as provitamin $\mathrm{A}$ carotenoids. Content of these lipid-soluble vitamins in fish eggs has been suggested to permit larger initial egg size, which in turn has been correlated with larger larval size and better early survival (Laevens et al., 1999). The primary function of vitamin $\mathrm{E}$ is to serve as an antioxidant, and it is by far the most physiologically important one in most vertebrates (Packer, 1991). As such, vitamin E plays an important role in protecting eggs during early development. Vitamin A and carotenoids are antioxidants too, but that is not their primary function. Vitamin A is required for growth, reproduction, maintenance of epithelial tissues and embryonic development of fish. It is present in many forms with at least some of those forms being potent morphogens in the developing embryo. Like vitamin E, vitamin A and carotenoids cannot be synthesised by fish and the amount of each deposited into the egg is a critical factor in determining reproductive fitness.

Here we review the literature regarding the content of vitamin $\mathrm{E}$ and vitamin $\mathrm{A}$ as well as provitamin A carotenoids in fish eggs, and the relationship of these micronutrients to larval development and reproductive fitness in general. Vitamin A has many other functions in the developing embryos that are more prominent than its activity as an antioxidant. However, these functions have been reviewed elsewhere, so this review will consider primarily the antioxidant roles of vitamin A and carotenoids. We have also emphasised the developmental processes of species with larger eggs and longer pre-hatch developmental periods, in which yolk constituents would be expected to play a larger role in determining fitness.

\section{ROLE OF VITAMIN E IN SUPPORTING REPRODUCTION}

Vitamin E is actually a collective term referring to two structural types of molecule: tocopherols and tocotrienols (Fig. 1). Both molecule types consist of a phytyl tail, which is embedded in the lipid membrane of cellular and subcellular membranes, and a chroman head, which protrudes to the inner or outer surfaces of the membrane. Tocotrienols differ from 

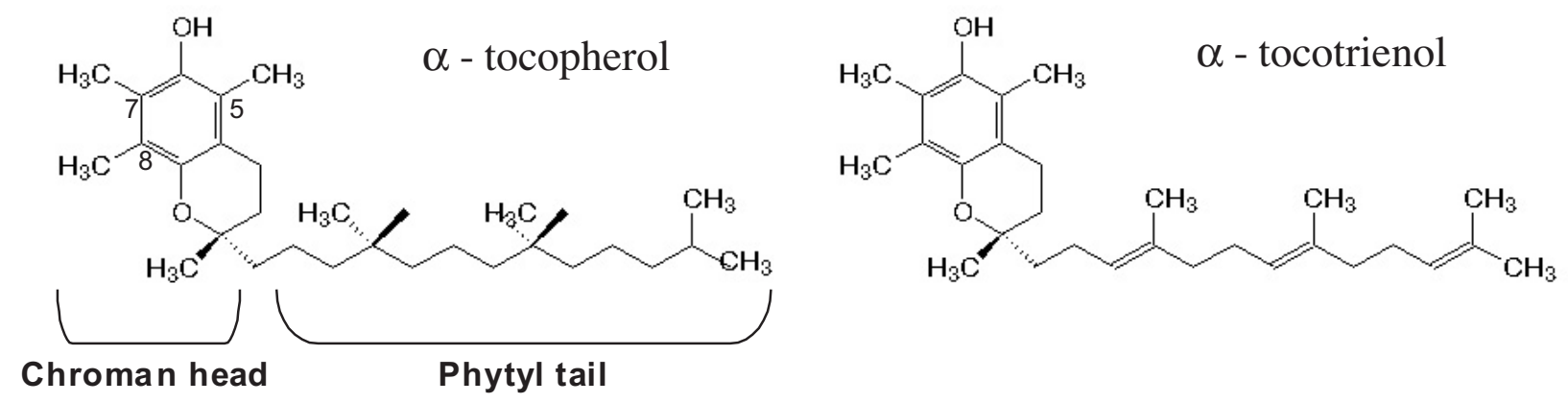

\section{Position of $\mathrm{CH}_{3}$ groups on tocopherol or tocotrienol aromatic ring (carbons 5,7 and 8 are labelled):}

$\begin{array}{lll}5,7,8 & = & \alpha \\ 5,8 & = & \beta \\ 8 & = & \delta\end{array}$

FIG. 1. - Chemical structures of tocopherols and tocotrienols.

tocopherols by having an unsaturated phytyl tail. The hydroxyl group(s) situated on the chroman head of either tocopherols or tocotrienols are the centre of the vitamin's antioxidant activity. This moiety is typically sacrificed to reduce ROS or lipid peroxyl radicals before they can damage other cellular components (Dimascio et al., 1991). By virtue of this ability, one tocopherol molecule can protect up to 1000 lipid molecules in the membrane (Liebler, 1993). In addition to the $\alpha$ forms illustrated in Figure 1, there are other forms of both tocopherols and tocotrienols that arise from different substituents that are possible on the aromatic ring. The known forms, with their substituents at positions 5, 6, 7, and 8 are also shown in Figure 1. It is important to recognise that the different forms have different potencies in vivo. The biopotencies of tocopherols, defined as the absorption in the gut, are in the order $\alpha$-tocopherol $>\beta$ tocopherol $>\gamma$-tocopherol $>\delta$-tocopherol, and $\alpha$ tocotrienol, which has approximately $25 \%$ of the biopotency of $\alpha$-tocopherol (Deshpande et al., 1996). However, in some situations, tocotrienols may be even more effective as antioxidants because of their higher mobility in the membrane structure. This is attributable to their unsaturated phytyl tail relative to tocopherols (Serbinova et al., 1991).

The requirement for vitamin $\mathrm{E}$ as an essential dietary component in fish has long been recognised, and minimum requirements for many fish species have already been established. For example, salmonid fish generally require 30 to $60 \mathrm{mg}$ of Vitamin E per kg of dry diet, with deficiency syndromes appearing as early as 16 weeks in fish fed deficient diets (King, 1985). However, minimum dietary concentrations of vitamin $\mathrm{E}$ are to be regarded as a tenuous guideline because the level of vitamin E required is highly dependent on the amount of fatty acids and PUFA lipids in the diet and the degree of their unsaturation (Baker and Davies, 1996). In the case of very high concentrations of PUFA and insufficient vitamin E content, yolk sac hypertrophy and decreased survival can result, presumably from oxidative stress type lesions. Fernández-Palacios et al. (1998) showed that hypertrophy and larval mortality could be reduced in high PUFA containing gilthead seabream (Sparus auratus) that were supplemented with vitamin $\mathrm{E}$.

Dietary concentrations of selenium, sulphur containing amino acids, other antioxidants, iron, vitamin $\mathrm{A}$ and $\mathrm{C}$, choline and quinines can also affect the rate of vitamin $\mathrm{E}$ supplementation required in the diet of fishes (Draper, 1980). Some of these dietary factors can influence the effectiveness of, and requirement for, vitamin $\mathrm{E}$ as an antioxidant. For example, it is thought that lower in vivo concentrations of antioxidants like vitamin C (Hamre et al., 1997) can increase the requirement for vitamin $\mathrm{E}$. This relationship appears to be most strongly evident when vitamin $\mathrm{C}$ is present at significantly deficient levels (Hamre et al., 1997). 
Environmental factors can also influence the rate of utilisation of the vitamin. For example, because temperature can affect the fatty acid composition of fish tissues, it is probable that vitamin E requirements are also affected by temperature (Hilton, 1989). Finally, the requirement for vitamin $E$ in the diet can be affected by exposure to many toxic inorganic and organic contaminants found in the environment. We have previously reviewed three categories of environmental contaminants that can affect vitamin $\mathrm{E}$ requirements or content in fish, including metals and metalloids, polyaromatic hydrocarbons and related organic contaminants and endocrine active contaminants, specifically environmental estrogens (Palace et al., 2006).

While the role of vitamin $\mathrm{E}$ in supporting reproductive processes has been known for decades in mammals, this role in fish was only conclusively demonstrated as late as 1990 by Watanabe. Higher concentrations of vitamin $\mathrm{E}$ are thought to reduce the percentage of abnormal eggs and increase overall fecundity (Izquierdo et al., 2001). Vitamin E is mobilised to the oocytes from peripheral tissues and muscle in adult female fish during oogenesis. Vitamin E metabolism, in general, is mediated by lipoprotein particles, with the transport essentially taking place in two parts (Lie et al., 1993; Hemre et al., 1994a). The first part of the transport moves lipids from the gut to the liver in the form of chylomicrons and fatty acids bound to carrier proteins. This is known as the exogenous portion of lipid metabolism. The second phase or endogenous portion of lipid metabolism exports lipids from the liver to the peripheral tissues packaged in very low density lipoproteins (VLDL), low density lipoproteins (LDL) and high density lipoproteins (HDL). In female fish, there is also a very high density lipoprotein fraction (VHDL) that consists mainly of the egg yolk precursor, vitellogenin (VTG) (Lie et al., 1994). Hung et al. (1982) reported that for rainbow trout (Oncorhynchus mykiss) vitamin E was found mostly in the VLDL fraction. Lipid soluble vitamins, including vitamin E, are primarily transported via passive inclusion in these hepatically derived lipoprotein particles, although there has been demonstration of protein mediated transfer of vitamin E within the liver of Atlantic salmon (Salmo salar). This protein transfer appears to preferentially incorporate $\alpha$-tocopherol more than $\gamma$ or $\delta$ isoforms, allowing $\alpha$-tocopherol to be retained to a greater degree (Hamre et al., 1998).
When fish are fed diets high in vitamin E, the vitamin accumulates in all tissues. However, prior to spawning a large portion is redistributed to the ovary (King, 1985). This mobilisation is critical for the development of embryonic fish. To examine the effects of vitamin $\mathrm{E}$ on egg development and the critical window for vitamin E requirement, King (1985) fed rainbow trout diets sufficient (88 to 96 $\mathrm{mg} / \mathrm{kg}$ dry weight) or deficient (non-detectable concentrations) in vitamin $\mathrm{E}$ for various time frames in the 7 months prior to spawning. The resultant fry were also fed diets deficient in vitamin $\mathrm{E}$ to examine requirements for the vitamin during early development. Plasma tocopherol was found to be highest in July, at the beginning of the experiment, in the deficient and sufficient groups. By January, when the fish had spawned, the plasma tocopherol was lower in fish that had been deprived of tocopherol, whether that deprivation took place for $1,3,5$ or 7 months prior to spawning. Measurements of muscle tocopherol showed that this tissue increased its tocopherol content between July and August but that from August to October muscle tocopherol concentrations dropped in the deficiently fed fish, but not in the sufficiently fed fish. Liver vitamin E also increased from July to August, but then declined until spawning in both of the groups.

When tococopherol concentrations were measured in the eggs (on a wet weight basis), an increase from $125 \pm 12 \mathrm{mg} / \mathrm{g}$ to $189 \pm 18 \mathrm{mg} / \mathrm{g}$ in August was reported for the fish fed the sufficient diet. There was no statistical difference from the eggs obtained from the deficient diet groups. In October, the concentration of tocopherol decreased to $86 \pm 6 \mathrm{mg} / \mathrm{g}$ in both groups. In December, the concentration of tocopherol increased slightly in fish receiving the sufficient diet but decreased in the deficient group, leading to a significant difference between the groups at the end of this period $(112 \pm 11 \mathrm{mg} / \mathrm{g}$ versus $69 \pm 5 \mathrm{mg} / \mathrm{g}$ ). When the amount of tocopherol was examined, rather than the concentration on a weight basis, tocopherol increased from July to spawning, doubling from $0.24 \pm 0.07 \mathrm{mg}$ to $0.66 \pm$ $0.22 \mathrm{mg}$ in both the sufficient and deficient groups. In October the amount increased to 1.45 to $1.93 \mathrm{mg}$. There were no statistical differences between the diet groups in any of these sample periods. In December, tocopherol amounts increased again, and there was significantly more tocopherol in eggs from the sufficient group $(6.25 \pm 0.78 \mathrm{mg})$ compared to the deficient group $(3.56 \pm 0.34 \mathrm{mg})$. 
The rate of deposition of vitamin $\mathrm{E}$ to eggs was greatest between October and December in fish fed the vitamin E sufficient diet. Furthermore, if vitamin E was removed from the diet after October, it had little effect on egg content of the vitamin. This means that vitamin $\mathrm{E}$ in the diet is most important for rainbow trout at least 3 months prior to spawning. The onset of ovarian maturation was clearly marked in July by a 3-fold increase in plasma tocopherol which paralleled the mobilisation of liver tocopherol. King (1985) goes so far as to suggest that the increase in plasma tocopherol could be used as a marker for the onset of gonadal maturation in rainbow trout. She also stressed that the liver appears to be the primary storage organ for tocopherol. Previous work had shown that muscle was the primary storage organ (Kimunaki and Sugii, 1972), but King (1985) found that the muscle became important only after the initial mobilisation of tocopherol occurred from the liver in July (6-7 months before spawning). That is, the liver moves most of its tocopherol to the muscle in July and August, and then this becomes mobilised from the muscle to the ovary during final gonad maturation. Schiedt et al. (1988) reported similar results for Atlantic salmon. Hemre et al. (1994b) also showed that stores of vitamin $\mathrm{E}$ were mobilised to the gonad prior to spawning. In turbot (Scopthalmus maximus) fed a commercial diet containing $285 \mathrm{mg} / \mathrm{g}$ vitamin $\mathrm{E}$ equivalents, liver, plasma and muscle vitamin $\mathrm{E}$ concentrations declined as gonads enlarged during the reproductive cycle. Ovary concentrations of approximately $100 \mathrm{mg}$ vitamin E/g wet weight were reported in that tissue prior to spawning.

By measuring tocopherol content and weighing tissues, King (1985) was able to calculate the total amount of tocopherol in the fish from both groups. The sufficient fish had approximately $35 \mathrm{mg}$ of tocopherol while the deficient fish had $25 \mathrm{mg}$. In July, the proportion of tocopherol in the ovary was $2.5 \%$, while the liver was the primary storage organ, accounting for approximately $45 \%$ of the total body pool of tocopherol. Muscle accounted for $19 \%$ and plasma for $15 \%$. At spawning, the ovary accounted for $50 \%$ of the total tocopherol pool in sufficient fish with $22 \%$ in muscle, $6.4 \%$ in plasma and $1.5 \%$ in liver. In the deficient fish, ovary accounted for $55 \%$ of tocopherol while liver was $1.7 \%$, muscle $20.5 \%$ and plasma $4.4 \%$. It would appear from these data that the deficient fish were able to divert a greater proportion of their overall tocopherol pool to the ovary. However, 5 out of 8 fish in the deficient group failed to spawn, and one had abnormal eggs, while all 8 from the sufficient group spawned. Females fed the deficient diet also tended to spawn later than those fed the sufficient diet.

Tokuda et al. (2000) fed Japanese flounder (Paralichthys olivaceus) a diet supplemented with vitamin E $(100 \mathrm{mg} / 100 \mathrm{~g})$ or a control diet $(1.6$ $\mathrm{mg} / 100 \mathrm{~g}$ ) for a period of 1 year. Tissues were then analysed for vitamin content at three periods: 1 month prior to spawning, at the peak of spawning and 3 weeks after spawning. Eggs collected from each of the groups were not different in their moisture, crude protein or crude lipid content, but the vitamin-supplemented group had $7.04 \pm 1.5 \mathrm{mg}$ vitamin E/100 g, while the unsupplemented group had only $1.16 \pm 0.14 \mathrm{mg} / 100 \mathrm{~g}$. The authors also measured vitamin $\mathrm{E}$ in the tissues of the adult male and female fish. They found that the vitamin E content was higher in gonad and lower in serum and liver of unsupplemented female fish when compared to male fish. The same pattern was evident for the supplemented fish, but with higher overall values of the vitamin in each of the tissues. Gonad tissue in the unsupplemented females contained 34 to $48 \mathrm{mg} / 100 \mathrm{~g}$ and in supplemented females it contained approximately $490 \mathrm{mg} / 100 \mathrm{~g}$ in both the mid-spawn and-post spawn periods. When serum lipoproteins were separated by electrophoresis and the tocopherol in each fraction was quantified, the authors found that those fractions containing VTG also contained a large fraction of tocopherol. Furthermore, when VTG production fell in the post-spawn period, vitamin E content in the serum also declined by a similar amount, indicating that VTG has an affinity for vitamin E and is a mechanism for translocating that vitamin to the developing ovary and egg. However, the binding of tocopherol to VTG accounted for less than $20 \%$ of the total serum vitamin E, so VTG is not the major transporter of vitamin E. Vitamin E was bound significantly to another lipoprotein band, suggesting that this fraction may be important for moving vitamin $\mathrm{E}$ from the ovary to other tissues after the spawning event. Finally, it was noted that tocopherol supplementation stimulated multiple spawning. That is, females in the supplemented group maintained their gonadal somatic index from the peak spawn to the post-spawn period and spawned 1.5 times more eggs than the unsupplemented group. 
More evidence for the relatively minor importance of VTG in transporting vitamin E was provided by Lie et al. (1994) in their studies of the transport of vitamin E in Atlantic salmon (Salmo salar). In these studies, juvenile Atlantic salmon were fed one of 6 experimental diets for a period of 24 months. The diets contained one of two tocopherol concentrations (low $=60 \mathrm{mg} / \mathrm{kg}$ or high $=270 \mathrm{mg} / \mathrm{kg}$ ) and one of three lipid sources. The basal diet was fish meal, and the other 2 formulations had $16 \%$ of either soybean or sardine oil sprayed onto the pellets after extrusion. Lipoproteins were isolated by sequential ultracentrifugal flotation. Fish fed the low tocopherol feed also had lower concentrations of the vitamin in muscle, liver and ovary. There was also a reduction in tocopherol in all tissues from July to September, with the largest reduction $(65 \%)$ seen in the liver of fish fed both the low and high vitamin $\mathrm{E}$ diet. However, of the lipoproteins particles, the vitellogenin fraction (VHDL) contained the lowest concentration of tocopherol during the vitellogenesis period $(1.8$ to $3.0 \mathrm{mg} / \mathrm{ml}$ serum for the low tocopherol group and 3.9 to $4.0 \mathrm{mg} / \mathrm{ml}$ for the high tocopherol group), while the HDL fraction contained the greatest quantity of vitamin E (14.4 to $25.9 \mathrm{mg} / \mathrm{ml}$ for the low and 37.5 to $70 \mathrm{mg} / \mathrm{ml}$ for the high). VLDL contained 9.6 to $13 \mathrm{mg} / \mathrm{ml}$ for the low and 21 to $34 \mathrm{mg} / \mathrm{ml}$ for the high tocopherol group and LDL contained 10.3 to $25.9 \mathrm{mg} / \mathrm{ml}$ for the low and 33.5 to $43.2 \mathrm{mg} / \mathrm{ml}$ for the high. Dietary lipid source had no effect on the proportions of tocopherol in the different lipoprotein particles. A large reduction was seen in the liver and muscle concentration of tocopherol during the last stage of vitellogenesis (September to November). In terms of the total amount of vitamin $\mathrm{E}$ in the fish, muscle contained the highest, accounting for approximately $75 \%$ of the fishes' vitamin E. Atlantic salmon do not eat during the latter stages of gonadal maturation, and therefore the remobilisation of nutritional stores from existing tissues is required for gonadal maturation.

The transfer of vitamin E from the yolk to the developing embryo is a gradual process that is probably associated with the assimilation of other lipids from the yolk. King (1985) reported that two weeks after hatching $50-66 \%$ of the tocopherol was still associated with the yolk. It appears that the transport from the yolk to the embryo is an efficient process, with virtually complete transfer of the vitamin from the yolk to the developing embryo. Takeuchi et al. (1981) measured tocopherol in developing offspring of ayu (Plecoglossus altivelis), showing that while concentrations of tocopherol changed in the yolk during development from fertilised eggs through embryonic development, the actual total amount of tocopherol in the embryo or larvae stayed the same at approximately $7 \mathrm{mg}$ tocopherol. Virtually all of the tocopherol in the yolk was transferred from the yolk to the developing fry, and the chorion contained only a negligible amount of the vitamin. Kimunaki and Sugii (1972) also found that tocopherol was transferred efficiently from the yolk to the fry in rainbow trout, with little consumption of the vitamin during development.

Vassalo-Aguis et al. (1998) found that a nearly 4fold difference between two experimental diets resulted in only slightly higher vitamin $\mathrm{E}$ content of eggs from fish fed a high $(327 \mathrm{mg} / \mathrm{kg})$ versus low $(85.8 \mathrm{mg} / \mathrm{kg})$ diet. They also found that newly hatched larvae had slightly higher vitamin E concentrations than eggs in the unsupplemented group (230-330 mg/g vs. $138-225 \mathrm{mg} / \mathrm{g}$ ), but relatively equivalent vitamin $E$ to the eggs in the group fed the high vitamin E diet (167 to 244 versus 180 to $218 \mathrm{mg} / \mathrm{g}$ ) (Vasallo-Aguis et al. 1998).

In contrast to the studies previously described, there is also some evidence that vitamin E concentrations do appreciably decline in fish eggs as they develop. For example, Cowey et al. (1985) found that vitamin E concentrations declined significantly in Atlantic salmon (Salmo salar) from the fertilised egg and eye stage $(\sim 3.1 \pm 0.13 \mathrm{mg})$ to the yolk sac $(2.93 \pm 0.05)$ and swim up $(2.29 \pm 0.11)$ stages. We have also reported slightly lower tocopherol concentrations in lake trout (Salvelinus namaycush) at the swim up stage relative to earlier stages of post hatch development (Palace et al., 1998a).

Several studies have examined the relationship between vitamin $\mathrm{E}$ concentrations in fish eggs and larvae and measures of reproductive success. In the previously described studies of King (1985), mortalities during the embryonic development of rainbow trout were divided into 2 phases. In the period up to eyed stage (220 degree days), there were no differences in mortalities between the fish fed a diet sufficient in vitamin $\mathrm{E}$ and those fed a deficient diet $(\sim 2 \%)$. After this initial period, all eggs were "shocked" by pouring them from a bucket into a tray of water from a height of $40 \mathrm{~cm}$. This common hatchery procedure ruptures the yolk membranes of unfertilised eggs or eggs in which development is not proceeding. In the post-shocking period, there 
were differences in the mortalities of the different diet groups. After shocking the mortality was higher and inversely related to the presence of vitamin $E$ in the diet. Fish always fed the sufficient diet had the lowest mortalities (2\%), while those receiving vitamin E from August to October had mortalities of 3\%. Those receiving vitamin $\mathrm{E}$ from December had mortalities of $5 \%$ and fish always fed the deficient diet had $11 \%$ mortality.

Ciarcia et al. (2000) quantified vitamin E concentrations in eggs and early development stages of the sea bass (Dicentrarchus labrax). Vitamin E concentrations in newly fertilised eggs were near 25 $\mathrm{mg} / \mathrm{g}$ in viable eggs, but less than $17 \mathrm{mg} / \mathrm{g}$ in dead eggs. The most dramatic decline in whole egg/larvae concentrations of tocopherol came during the first 4 days after fertilisation in viable eggs and by 12 days post-hatch concentrations had declined to around 8 $\mathrm{mg} / \mathrm{g}$ in samples of viable eggs. A similar decline was not evident in dead eggs collected at the same time points. The authors attribute the loss of vitamin $E$ in viable eggs to its use as an antioxidant during the early development when enzymatic defences are only just developing.

A similar rationale was cited by Mourente $e t$ al. (1999) for their examination of vitamin E concentrations in the eggs and early developmental stages of the marine common dentex (Dentex dentex). However, these authors found a relatively constant concentration of vitamin $\mathrm{E}$ in eggs and larvae up to 7 days after hatching (around $6 \mathrm{ng}$ of vitamin E per egg). Vitamin E did decline sharply over the next 2 days to less than half of the original content, but it should be noted that the larvae were starved during this period and died soon afterwards. No correlations were seen between the levels of oxidation breakdown, measured as malondialdehyde and lipid soluble fluorescent products, and declining vitamin E concentrations. In fact, because PUFA concentrations declined over the course of larval development, the ratio of vitamin E to PUFA increased slightly. The authors concluded that peroxidation was not a significant factor in the Dentex eggs.

Fernández-Palacios et al. (1998) fed gilthead seabream (Sparus auratus) diets containing either 1.6 or $2.5 \mathrm{~g} / 100 \mathrm{~g}$ of highly unsaturated fatty acids (HUFA) and one of four concentrations of vitamin $\mathrm{E}$ ranging from 20 to $2000 \mathrm{mg} / \mathrm{kg}$. Egg concentrations of vitamin $\mathrm{E}$ were found to increase proportionally with vitamin E supplementation. Egg viability and the percentage of abnormal eggs was improved at higher dietary alpha-tocopherol concentrations (Fernández-Palacios et al. 1998).

Eskelinen (1989) fed Atlantic salmon (Salmo salar) five different dry and five different semi-dry feeds. They also had a group fed only smelt (Osmerus eperlanus) for 6 months prior to spawning. The feeds differed in their moisture and lipid content and in the amount of vitamin E that they contained. The semi-moist feeds contained between 4.7 and $9.6 \%$ fat and 57 and $88 \mathrm{mg} / \mathrm{kg} \alpha$-tocopherol and the dry feeds contained between 8.5 and $21.5 \%$ fat and 89 to $370 \mathrm{mg} / \mathrm{kg}$ of $\alpha$-tocopherol. The smelt contained $3.4 \%$ fat and $24 \mathrm{mg} \alpha$-tocopherol per $\mathrm{kg}$. Eggs from 6 females in each diet treatment were incubated separately and evaluated for survival to the eyed, hatching and end of start feeding stages. Females in each group were also evaluated for fecundity, gonad size relative to body size, egg volume and egg size. They found no increased reproductive performance in fish supplemented with vitamin E. The authors suggest that although Watanabe et al. (1985) recommended at least $100 \mathrm{mg} / \mathrm{kg}$ of $\alpha$ tocopherol be supplemented to feed, the performance of their fish was adequate, because they may have been able to mobilise stores of vitamin $\mathrm{E}$ to the gonads that were present in peripheral tissues before the feeding trial ever began.

\section{VITAMIN A AND EARLY DEVELOPMENT}

Vitamin A is required for growth, reproduction and embryonic development of fish and must be obtained from the diet, because fish are incapable of synthesising the vitamin (Craik, 1985; Madden, 2001).Vitamin A is present in fish in many forms, including the free alcohol form retinol (Vitamin A1) and the closely related dehydroretinol (Vitamin A2) form, which differs from vitamin A1 by only one double bond (Fig. 2). Because the free alcohol form of vitamin A can be toxic to cells, many tissues, most notably the liver, adipose tissue and kidneys, store vitamin A1 and A2 as esters of long chain fatty acids (e.g. retinyl palmitate and retinyl stearate and their vitamin A2 analogues dehydroretinyl palmitate and dehydroretinyl stearate) (Palace and Brown, 1994). Retinal is the form of vitamin A required for vision. It can also exist in the A2 form. Several isoforms of retinoic acid are generated by conversion of retinol to retinal by alcohol dehydrogenase enzymes and then to retinoic acids by the activity of 


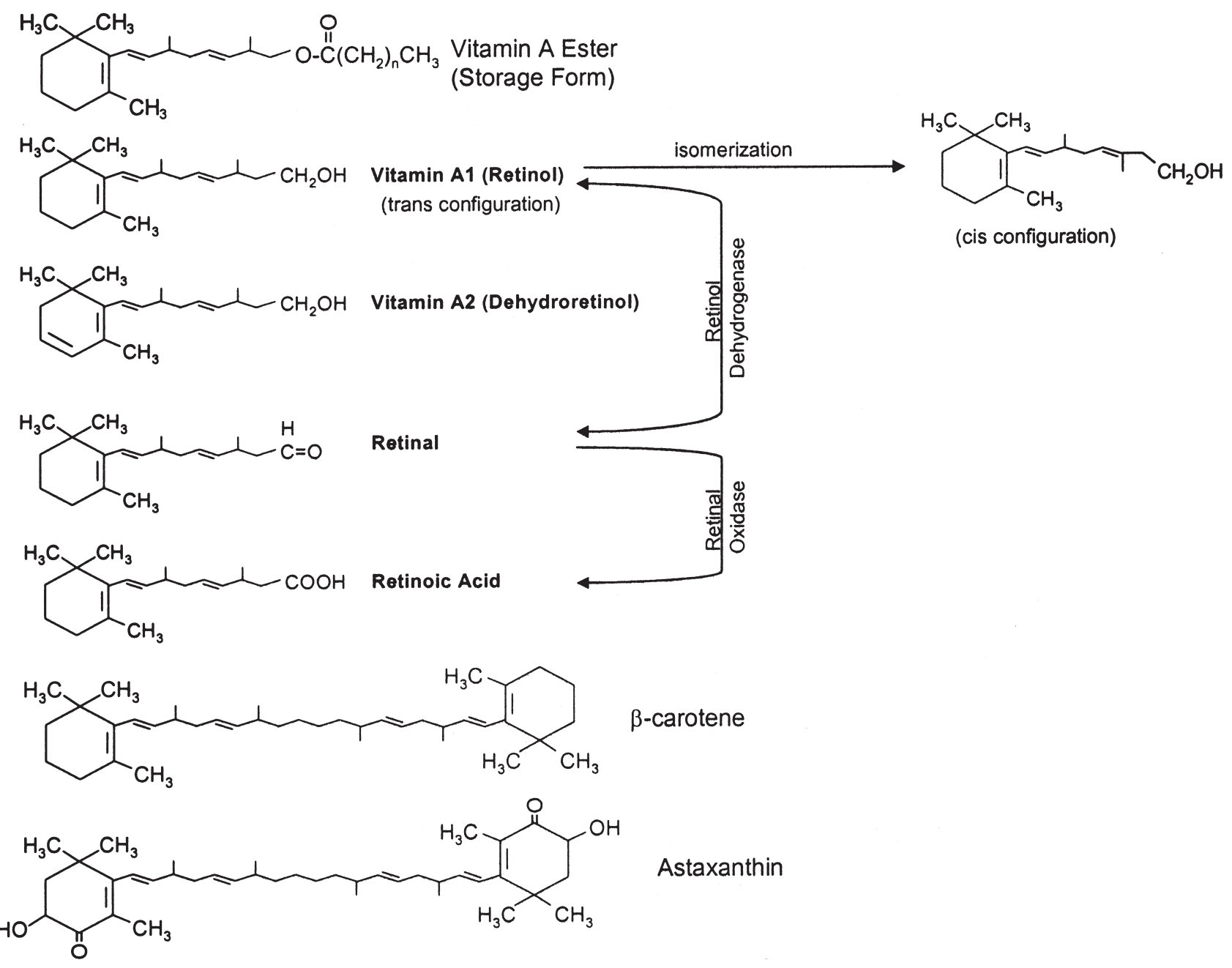

FIG. 2. - Chemical structures of the most common forms of vitamin A and carotenoids. Conversion pathways for retinol to retinal and retinoic acid are shown with the enzymes responsible for these conversions.

aldehyde dehydrogenases (Duester, 1996). The rate limiting step for retinoic acid formation is determined by the activity of retinol dehydrogenase (Chen et al., 1995). Retinoic acids are potent morphogens that provide axial patterning information in developing vertebrates (Means and Gudas, 1995). Vitamin A forms can exist as either the trans or cis isomers (Fig. 2) and activity potency can be greatly different between the two isoforms, particularly for the retinoic acids.

It has been recommended that carotenoids, primarily astaxanthin and canthaxanthin, be included in the feed of broodstock at a level of $10 \mathrm{mg} / \mathrm{kg}$ dry weight (Torrissen and Christiansen, 1995). Unlike the condition for vitamin E, in which hypervitaminosis has not been described, high concentrations of vitamin A can be problematic, giving rise to growth depression, increased mortality, abnormal fins and pale livers (Furuita et al., 2001). Toxic levels of vitamin $\mathrm{A}$ in the diet range from $40 \mathrm{IU} / \mathrm{g}$ for tilapia (Oreochromis niloticus) to $2000 \mathrm{IU} / \mathrm{g}$ for fingerling rainbow trout (Oncorhynchus mykiss) (cited in Furuita et al., 2001). Skin lesions are often the first signs of hypervitaminosis (Furuita et al., 2001). High concentrations of carotenoids are not normally toxic, the only side effect being darker colouration of muscle tissue.

Carotenoids are transported in an analogous manner to that we have already described for tocopherol. That is, they are delivered to the liver from the intestine packaged in chylomicrons and then redistributed in lipoprotein particles. LDL, HDL and VHDL have been reported to contain 5, 32 and 34\% of the total circulating carotenoids in chum salmon (Oncorhynchus keta) (Ando et al., 1985). Aas et al. (1999) further showed that a large portion of the 
total carotenoids were associated with albumin in Atlantic salmon (Salmo salar). The HDL fraction appears to be important for transporting carotenoids from the muscle to the skin during spawning times in salmonids. Similarly, transport of vitellogenin in VHDL corresponds to the transport of a large pool of carotenoids to eggs (Lubzens et al., 2003).

Similar to the situation for carotenoids, the transport of VTG has been shown to correspond with deposition of retinoids in eggs (Irie and Seki, 2002). However, it should be noted that because of their potentially toxic nature, the handling of retinoids must be actuated differently than the more passive inclusion of carotenoids in lipoprotein particles. Retinoids are transported in plasma bound to retinol binding protein, and to some extent bound to albumin (reviewed in Lubzens et al., 2003). We have previously shown that treatment of fish with estradiol or its analogues results in elevated concentrations of the vitamin in plasma and depleted stores in storage organs, perhaps as a result of translocation of the vitamin to the developing ovaries (Palace et al., 2001a,b). Similar results have been reported by Sammar et al. (2001 as cited in Lubzens et al., 2003). It appears that as spawning approaches and estrogen levels peak, there is no significant regulation of mRNA for retinol binding proteins in the liver, but there is certainly an increase of mRNA for VTG. This may allow for lower retention of retinol in the liver and greater inclusion of the vitamin with VTG as it is exported from the liver to the blood, eventually making its way to the ovary. Lubzens et al. (2003) recently reported the synthesis of RBP in ovarian tissue of rainbow trout (Oncorhynchus mykiss), indicating that active uptake may play a role in determining egg content of retinol.

To serve as provitamin A compounds, carotenoids (e.g. $\beta$ - and $\alpha$-carotene, astaxanthin and canthaxanthin) must be cleaved to yield retinol or other forms of vitamin A. There are approximately 600 different carotenoids known to exist, but only about 50 of these have provitamin A activity (Olson, 1989). All carotenoids contain a repeated isoprenoid pattern in their hydrophobic inner structure and may either have closed phenolic groups at the ends of the molecule (e.g. $\beta$-carotene) or exist as an open structure (e.g. lycopene). Their structures confer particular absorption spectra, giving rise to the characteristic pink, yellow and orange colouration of muscle and eggs. Proportions of carotenoids vary with the dietary composition of fish (Lubzens et al., 2003), but the major carotenoid pigment in salmonids is astaxanthin, which is responsible for the pink colour of the flesh (Schiedt et al., 1985). Theoretically, $\beta$ carotene can be cleaved in the centre of its isoprenoid chain to yield 2 retinal molecules. However, differences in intestinal absorption rates, susceptibility to oxidation and the ability to be converted into retinal, retinoic acid and retinol all contribute to the fact that -carotene provides less than $50 \%$ of the biological activity of vitamin A (Olson, 1989), with the accepted conversion rate being approximately 6:1 in humans (Wang, 1994). Other carotenoids support vitamin A function in varying degrees, being converted to either A1 or A2 compounds, depending on structural considerations and conversion rates (reviewed in Torrissen and Christiansen, 1995). Xanthophylls have been proposed to be precursors of vitamin A2 (dehydroretinol) (Schiedt et al., 1985). Lutein has also been proposed to be a precursor of vitamin A2 (Goswami, 1988). Gross and Budowski (1966) found evidence for the conversion of astaxanthin, canthaxanthin and zeaxanthin via $\beta$-carotene to vitamins A1 and A2 in guppies and platties. While early work (Hata et al., 1973) contended that the salmonids cannot, like other fishes, transform carotenoids obtained from their diet, Kitahara (1984) showed that considerable conversion of carotenoids occurred during the development of chum salmon (Oncorhynchus keta) eggs. They documented that astaxanthin was the predominant carotenoid detectable in eggs, and that after yolk absorption at least 8 carotenoids could be identified. In freshwater fish in which more vitamin A2 is normally present, there appears to be more zeaxanthin and lutein in eggs (Hata and Hata, 1971). Lubzens et al. (2003) reviewed studies which quantified concentrations of carotenoids in fish eggs and showed that eggs from marine teleosts contain $10-25 \mathrm{mg}$ carotenoids per gram of dry egg weight, while freshwater teleosts contained less than $1 \mathrm{mg} / \mathrm{g}$.

In addition to the carotenoids found in fish eggs, there are several forms of vitamin A1 and A2 that are present in the egg. Plack et al. (1959) were the first to demonstrate the appearance of retinal in eggs of herring (Clupea herengus). Since then, there have been numerous quantifications of retinal and retinol as well as vitamin A2 analogues (reviewed in Lubzens et al., 2003). Typically, marine and freshwater teleosts contain 2-14 mg retinal per dry gram of eggs, 0.5 to $7 \mathrm{mg} / \mathrm{g}$ of retinol and retinol esters. It 
appears that marine teleosts contain slightly higher proportions of retinal and dehydroretinal, while freshwater teleosts contain higher proportions of retinol and dehydroretinol. Lubzens et al. (2003) speculated that the absorption ranges of retinal and dehydroretinal may reflect light at different ranges from retinols and factored in reduced predation of pelagically developing eggs.

The role of vitamin A and carotenoids for determining egg and early life stage quality has been a controversial subject for over 50 years (Izquierdo et al., 2001; Craik, 1985). The few available carefully designed studies suggest that enhanced concentrations of some carotenoids are associated with better egg condition and increased measures of survival. As in amphibians, the predominant form of vitamin A in many fish eggs is retinal, but retinol, retinyl esters and carotenoids can also be found in significant quantities (Irie and Seki, 2002). In fact, the bright yellow orange or red colour of many fish eggs is due to the presence of carotenoid pigments (Craik, 1985). Salmonids generally take up carotenoids, predominantly, canthaxanthin and astaxanthin, from the diet and deposit them in muscle. These stores can then be mobilised to eggs via very high density lipoproteins (VHDL) or VTG or high density lipoproteins (Torrissen and Christiansen, 1995). This active transfer has led to the hypothesis that carotenoids are critical to the development of egg and larval development (Torrissen and Christiansen, 1995).

The concentrations of carotenoids and vitamin A forms in eggs of teleost fishes varies widely and can even vary widely within a species, as reviewed by Craik (1985). Carotenoids are generally more concentrated in eggs of salmonids in which post-fertilisation development takes place in low oxygen environments (i.e. gravel and or silty sediments) than in eggs that develop in a pelagic environment. In these cases it has been suggested that carotenoids confer some ability on the eggs to develop more adequately in low oxygen environments. Early suggestions for this resistance hinted at the ability of carotenoids to serve as an oxygen source under anoxic conditions (reviewed by Craik, 1985), but this activity may be more related to the preferential use of carotenoids as antioxidants over tocopherol under low oxygen tensions (Burton and Ingold, 1984; Palozza and Krinsky, 1992). Furthermore, in pelagic eggs higher contents of pigment in the form of carotenoids would confer an evolutionary disadvantage as these eggs would be more visible and more easily predated upon (Craik, 1985).
Irie and Seki (2002) found only retinal-1 in the eggs of three marine species (black porgy, Acanthopagrus schlegeli; marbled flounder, Pleuronectes yokohamae; and stingfish, Inimicus japonicus), but both retinal-1 and retinal-2, as well as retinol in the eggs of the anadromous chum salmon (Oncorhynchus keta). Most of the retinal was in the all trans form with a small amount of the cis isomers present. Retinol accounted for less than $1 \%$ of the total retinoids in the eggs in the chum salmon eggs. Retinyl esters were only detected in the two species that have lipid bodies in their eggs: chum salmon and black porgy. Retinyl esters accounted for up to $42 \%$ (average $30 \%$ ) of the total retinoids in chum salmon eggs with vitamin A1 esters predominating by a ratio of 9:1 over dehydroretinyl esters. Black porgy had a detectable retinyl ester complement, accounting for about $8 \%$ of the total retinoid complement. Further characterisation of the localisation of retinoids in the eggs of chum salmon showed that the retinals were bound to the protein fraction of egg yolk, most likely to the egg yolk protein lipovitellin-1 (Irie and Seki, 2002). It is interesting to note that retinal appears in the ovaries of cod after the onset of production of VTG, the precursor of lipovitellin-1 (Plack et al., 1961).

Steffens and Karst (1965) reported vitamin A content in rainbow trout eggs to be near $3-4 \mathrm{mg} / \mathrm{g}$. These authors also later reported that b-carotene could be converted to vitamin A in rainbow trout fry (Steffens and Karst, 1972). We have reported retinol in eggs of lake trout at $1-2 \mathrm{mg} / \mathrm{g}$ and the predominant carotenoid, astaxanthin, of $2-3 \mathrm{mg} / \mathrm{g}$ in eggs (Palace et al., 1998a). Both parameters declined in whole embryo through development to the swim up stage. An increase in retinol has been shown in liver of turbot fed a commercial diet containing $5.2 \mathrm{mg} / \mathrm{g}$ vitamin A equivalents during gonadal maturation as the length of the day increased, but retinol concentrations in plasma were held relatively constant and retinol content in gonads was actually reduced during maturation (Hemre et al., 1994a). No correlation was evident between liver retinol and gonad weight expressed versus body weight.

Fox and Vevrs (1960) first described a phenomenon whereby the serum of chum salmon became brightly coloured during anadromous migration, and characterised the colouration as being due to the presence of astaxanthin. The timing of this colour change in serum, concomitant with a lightening of flesh colour and during gonadal development, sug- 
gested a transfer of the carotenoid from muscle to ovary. Kitihara (1983) examined carotenoids in chum salmon at the beginning of their anadromous migration and at the end of the period. He found that carotenoids ( $\sim 90 \%$ astaxanthin) drastically decreased in muscle during the spawning period (from 0.65 to about $0.04 \mathrm{mg} / 100 \mathrm{~g}$ ). This represents a drop of about $93 \%$. Carotenoids accumulated in the skin and the gonads, again with astaxanthin being the most abundant carotenoid. The authors speculated that lipoprotein particles were responsible for transporting the carotenoids.

Kitihara (1983) reported that astaxanthin was converted to other carotenoids in the skin during final migration. This transformation could be an important determinant of spawning coloration. Carotenoids could serve an important function as pigments as they relate to communication in fishes. Fish are capable of changing their colour through both hormonal and neuronal control of chromatophores, of which carotenoids are major constituents (Torrissen and Christiansen, 1995). An early study by Stevens (1949) using brown trout (Salmo trutta), which had been ligated to remove the lipid globule and associated carotenoid pigmentation, showed that alevins developed without red and yellow chromatophores. Other studies confirmed these early observations (Takeuchi, 1960). Hata et al. (1973) noted that carotenoids were stored in salmonid muscles and then were mobilised to the ovaries and eggs in females and to the skin of males in preparation for spawning. The carotenoids were suggested to function in adult males to attract mates and in females, it was proposed that xanthophylls can act as fertilisation hormones, to enhance growth, maturation rate and fecundity, and to reduce mortality during embryonic development. Carotenoids were also suggested to increase the survivability of embryos under harsh conditions like increased water temperature and high ammonia, and to protect from light damage, but these hypotheses have not been confirmed with empirical evidence.

Given that carotenoids are derived from plants, where they serve as secondary pigments to transfer light energy to the actual pigments involved in photosynthesis, it is not surprising that it is also thought that carotenoids provide some measure of protection against photoxidative damage in fish (Craik, 1985). However, the physiological importance of this protection may be minimal since salmonid eggs, which typically contain the highest concentrations of carotenoids, develop in the dark while submerged in gravel (Craik, 1985).

At least one study has examined the relationship between vitamin $\mathrm{A}$ and/or carotenoid content and reproductive success in fish, while including a component of light sensitivity. Torrissen (1984) found that fry fed astaxanthin- and canthaxanthin-supplemented feed $(30 \mathrm{mg} / \mathrm{kg}$ ) grew faster than fry fed unsupplemented feed. There was no difference in the effectiveness of the two carotenoids at stimulating this growth. The study went further to examine the interactive effects of light and carotenoid levels on the survival of differently pigmented Atlantic salmon (Salmo salar) eggs and developing larvae. Astaxanthin was the predominant carotenoid, but there were also appreciable amounts of canthaxanthin. Analysis of covariance showed that there was no effect of carotenoid content on the survival to the eyed, hatching or alevin stages. The effects of different types of light on survival of eggs with the same carotenoid concentrations was also examined. The eggs used for these studies ranged in carotenoid content from 2 to $5.5 \mathrm{mg}$ astaxanthin per kg of eggs. White light was found to be most damaging to the eggs on the basis of cumulative mortality (time to $50 \%$ mortality was 18 days), while UV light caused $50 \%$ mortality at around 71 days. Yellow light did not initially affect mortality, but after eyeing the eggs had higher mortalities because of early hatching. The time to $50 \%$ mortality in the yellow-lightexposed eggs was about 93 days. The authors speculated that carotenoids may have functioned to protect the eggs from photosensitisation by quenching singlet oxygen or by acting as a filter for damaging light. Carotenoids in salmon eggs, however, are deposited in the yolk and collect in the oil globules a few days after fertilisation, so they would not be available for such a protective function in the embryos proper. Finally, it should also be noted that Torrisen (1984) documented greater sensitivity to light in eggs that had the highest amounts of carotenoids.

The detrimental effects of greater carotenoid content in the Torrisen (1984) study would seem to contradict the notion that carotenoids are beneficial to larval fish survival. However, some enlightenment may be provided by the results of a seemingly unrelated human dietary study. In this large scale study, carotenoid supplements were provided as part of a total antioxidant supplement intended to reduce the effects of oxidative damage arising from smoke 
inhalation in a population of smokers. The study had to be terminated early because the group of smokers receiving carotenoid supplements actually showed higher rates of lung cancer and cardiovascular mortality when compared to the unsupplemented group (Omenn et al., 1996). We have previously speculated that the increased rates of cancer could have been related to greater oxidative damage in the supplemented group. This oxidative damage may have arisen from carotenoid-mediated lipid radical damage (Palace et al., 1999). More specifically, because carotenoids are themselves unsaturated lipid structures, they too can participate in and propagate the lipid peroxidation process (Rousseau et al., 1992). This mechanism may have operated in Torrisens's experiments, in which the eggs with more carotenoids were more sensitive to light. Carotenoids could still be physiologically important antioxidants in fish eggs, particularly in those that develop in darker, less oxygenated environments, e.g. salmonids. That is because carotenoids are known to be more active scavengers of singlet oxygen under low oxygen tension situations (Palozza and Krinsky, 1992).

Carotenoids can scavenge singlet oxygen and peroxyl radicals. Singlet oxygen, a ROS, is unstable and highly reactive (Palace et al., 1999). The scavenging rates of singlet oxygen by carotenoids are in the range of $10^{8}$ to $10^{10} \mathrm{~mol}^{-1} \mathrm{~s}^{-1}$ and are even greater than tocopherol $\left(10^{8} \mathrm{~mol}^{-1} \mathrm{~s}^{-1}\right)$ (Ojima et al., 1993). Singlet oxygen can either be quenched physically by transfer of the excitation energy to a carotenoid with subsequent dissipation of that energy as heat and no loss of the carotenoid, or by chemical transfer with loss of the carotenoid molecule after the reaction. Generally the chemical reaction is only $5 \%$ of the physical activity with regard to singlet oxygen quenching (Sies and Stahl, 1995). Carotenoids also stabilise peroxyl radicals, which are probably of more physiological relevance in biological systems, including the developing embryo, than singlet oxygen. The quenching mechanism and site on the carotenoid molecule of the interaction and quenching ability for peroxyl radicals has been elusive, with several possibilities being proposed (reviewed by Palace et al., 1999). However, in general the peroxyl radical scavenging ability of a carotenoid is proportional to the length of the conjugated double bond section of the compound (Sies and Stahl, 1995). The antioxidant activities of Vitamin A compounds are also thought to arise from their ability to stabilise peroxyl radicals and perhaps even the potentially damaging glutathione radical (Tesoriere et al., 1993; D'Aquino et al., 1989). Using an in vitro peroxidation system, antioxidant activities of retinoids have been ranked as retinol>=retinal»retinyl palmitate>retinoic acid (Das, 1989).

The importance of maternal ability to control vitamin A metabolism and regulate, to some degree, vitamin A deposition to eggs to preserve egg quality and maintain early development was shown in experiments with Japanese flounder (Paralichthys olivaceus). Fish were fed either a control diet containing $110 \mathrm{IU}$ Vitamin A/g (as retinyl palmitate) or a supplemented experimental diet of 3370 IU Vit A/g for a period of two months prior to spawning and throughout the spawning period (Furuita et al., 2001). Retinol content was elevated nearly 20 times in the livers of adult female fish fed the experimental diet $(934 \mathrm{mg} / \mathrm{g}$ in controls versus $17336 \mathrm{mg} / \mathrm{g}$ in the experimental diet fish), but was only 4 times higher in eggs $(5.42 \mathrm{mg} / \mathrm{g}$ in eggs from the experimental diet fish and 1.35 from the control diet fish) and total retinoids were only 2 times higher in experimental versus control group fish $(13.6 \mathrm{mg} / \mathrm{g}$ versus $7.6 \mathrm{mg} / \mathrm{g}$, respectively). The authors noted that although one group had a far higher vitamin A dietary supplementation rate, for the most part the extra vitamin A was stored as retinyl esters in the livers of the mothers with only moderate increases in egg vitamin A content. Other differences in the types of retinoids were, however, evident between the groups. Specifically, retinal formed a larger component of the total retinoids in eggs from the control diet group (82\%) versus the experiment diet group (62\%). The percentage of buoyant eggs and the hatching rates were slightly, but significantly higher in the experimental diet group but egg production was not different between the groups, and other measures of reproductive performance (abnormal larvae and starvation tolerance) were not different, suggesting that the extra vitamin A did not adversely affect reproductive output of the flounders. Vassalo-Aguis et al. (1998) found that even when carotenoids were supplemented into the diets of striped jack (Pseudocaranx dentex) (at 5.3 or $7.7 \mathrm{mg} / \mathrm{kg}$ ) for four months before spawning, eggs contained non-detectable levels of carotenoids.

Craik (1985) provided a review of the studies of Murayama and Yanase (1961) in which carotenoid content and hatching success were measured in rainbow trout (Oncorhynchus mykiss) farmed at nine 
different facilities in Japan. The data indicate that eggs with lower carotenoid content (i.e. $<1-3 \mathrm{mg} / \mathrm{g}$ ) had lower hatching percentages and that this level was critical to egg performance. Furthermore, it appears that the concentration of astaxanthin, more than lutein, contributed to this effect. Craik (1985) also reviewed other evidence for the apparently "well accepted" link between carotenoid content and egg quality and found that many of the older available studies, many (6) in Russian and not translated to English, were not as carefully performed or scientifically sound as was originally portrayed, or that they had inconsistencies that resulted in uninterpretable data (see Craik, 1985 for an extended discussion of these studies). However, a few general conclusions can be drawn from the review of these early studies. First, egg colour is not a good indicator of carotenoid content since different carotenoids can impart darker colour at lower concentrations than other carotenoids (Craik, 1985). Second, hatchability, mortality and fertilisation percentages are comparable over wide ranges of carotenoid concentrations and only at low concentrations of carotenoids do reproductive parameters become impacted. This may explain why researchers examining correlations at high carotenoid levels have failed to find correlations between egg performance and carotenoids, while studies looking at low concentrations return more closely correlated data. Third, the levels of carotenoids deposited to eggs are under at least some metabolic control as even feeds with high concentrations of carotenoids result in only moderate increases in egg carotenoid content (Craik, 1985). Shnarevich and Sachenko (1972 in Russian but summarised in Craik, 1985) did provide some interesting results from rainbow and brown trout. They again found high fertilisation percentages over a wide range of carotenoids in rainbow trout (5.5 to $10.9 \mathrm{mg} / \mathrm{g}$ ) and in brown trout (9.9 to $16.0 \mathrm{mg} / \mathrm{g}$ ). Both of these were well above the critical level of 1$3 \mathrm{mg} / \mathrm{g}$ stated earlier. However, they went on to study the survival of young after the embryonic period and found significant correlations between carotenoid content of eggs and the survival to the end of the alevin stage for both species. Finally, Craik (1985) concluded that canthaxanthin can adequately replace the other more common dietary ketocarotenoid for wild fish, astaxanthin, as evidenced by good performance of farmed fish with canthaxanthin as their only source of carotenoids, and that hydroxyl-carotenoids such as lutein and zeaxanthin are not equipotent.

Christiansen et al. (1995) investigated the interactive effects of astaxanthin and vitamin $\mathrm{A}$ on growth and survival in first feeding fry of Atlantic salmon. They fed the salmon purified diets containing 0,20 or $40 \mathrm{mg} / \mathrm{kg}$ astaxanthin and 0,600 or 1200 $\mathrm{mg} / \mathrm{kg}$ of vitamin A as retinyl palmitate and retinyl acetate. After 135 days of feeding the diets, they found that both supplemented diets of astaxanthin improved growth and survival. Vitamin A alone did not support growth and survival. This seems to indicate that carotenoids serve purposes other than just provitamin $\mathrm{A}$ in the developing salmon embryo (Christiansen et al., 1995).

Harris (1984) fed rainbow trout diets fortified with a synthetic carotenoid source containing $10 \%$ canthaxanthin so that they received either 20 or 40 $\mathrm{mg}$ canthaxanthin $/ \mathrm{kg}$ of feed for 3 or 6 months. While the colour of the eggs intensified with the amount of canthaxanthin and the length of feeding time, this had no effect on the number of eggs per female or in the percentage of dead eggs at the eyed stage. Harris (1984) did report that the number of infertile females was highest in the control group of fish not supplemented with canthaxanthin. This is similar to the study of Deufel (1965), who found that $40 \mathrm{mg}$ of canthaxanthin added to fish diets increased the percentage of fertile females and also of fertilisation. Harris also reviewed evidence from other papers on the subject of carotenoid effects on fecundity and survival. In that review he noted that Hubbs and Stavenhagen (1958) found that greenthroat darters (Etheostoma lepidum) fed a diet of whiteworms that were deficient in carotenoids produced eggs with reduced survival. When females maintained on whiteworms were switched to a balanced diet with carotenoids, they soon produced eggs that had a higher survival rate. They also found that they could increase the viable number of offspring when carotenoids were added in the form of spinach extract, or by adding vitamin A to the diet. However, Quantz (1980) found no relationship to fertilisation in rainbow trout fed diets supplemented with canthaxanthin at $0.6,56.5$ or $92.0 \mathrm{mg} / \mathrm{kg}$ or with astaxanthin at $20 \mathrm{mg} / \mathrm{kg}$ for 8 - 15 weeks before spawning. Similarly, Morrison and Smith (1981) found no difference in fecundity of female brook trout fed a control diet or diets fortified with canthaxanthin and deep water red crab processing waste for 66 days prior to spawning. 
One of the most comprehensive examinations of the effects of vitamin $\mathrm{E}$ and $\mathrm{A}$ and carotenoid concentrations on egg quality and larval development was performed by Vasallo-Aguis et al. (1998). Their work also reflected species specific concerns, as some of the same research group had previously shown important differences in egg and larval quality related to carotenoids in the broodstock diet of yellowtail (Verakunpiriya et al., 1996). In those experiments, yellowtail were fed one of three diets; a raw fish (RF) diet containing $0.04 \mathrm{mg} / 100 \mathrm{~g}$ carotenoids, $24.5 \mathrm{IU} / \mathrm{g}$ vitamin A and $24.5 \mathrm{IU} / \mathrm{g}$ vitamin E, a moist pellet diet (MP) containing 2.79 $\mathrm{mg} / 100 \mathrm{~g}$ of carotenoids, $26 \mathrm{IU} / \mathrm{g}$ vitamin $\mathrm{A}$ and $471.8 \mathrm{IU} / \mathrm{g}$ of vitamin E, or a soft dry pellet (SDP) feed containing $86.73 \mathrm{mg}$ carotenoids per $100 \mathrm{~g}, 5.8$ $\mathrm{IU} / \mathrm{g}$ vitamin $\mathrm{A}$ and $124.1 \mathrm{IU} / \mathrm{g}$ of vitamin $\mathrm{E}$ (all on a dry weight basis). The differing diets resulted in correspondingly varying amounts of vitamin $\mathrm{E}$ in milt $(\mathrm{RF}=92.9, \mathrm{MP}=292.1$ and $\mathrm{SDP}=163.1 \mathrm{mg} / \mathrm{g}$ dry weight), but there was no effect on overall lipid composition of milt. Vitamin A content was undetectable in the milt from the RF fed fish, but $1.1 \mathrm{IU} / \mathrm{g}$ was present in the milt of MP fish and $1.2 \mathrm{IU} / \mathrm{g}$ in the milt of SDP fed fish. Vitamin E content in eggs also generally reflected the availability of the vitamin in the broodstock diets, with the eggs from the MP group having higher concentrations (187 to 243 $\mathrm{IU} / \mathrm{g})$ than the SDP $(90-138 \mathrm{IU} / \mathrm{g})$ and RF diets $(88$ $\mathrm{IU} / \mathrm{g}$ ). In the two groups (MP and SDP) in which vitamin $\mathrm{E}$ concentrations were assessed in the eggs at 3 stages of spawning (initial, middle and final spawnings), vitamin E content generally declined from the initially spawned eggs to the final spawned eggs. The reduction was in the range of 23 to $34 \%$. It has been suggested that for multiple spawners like the yellowtail a continuous supply of essential nutrients must be provided in order to maintain egg quality (Fernadez-Palacios et al., 1997). Vitamin A concentrations in eggs did not reflect the availability of the vitamin in the diet as closely as for vitamin E. Whereas the supply of vitamin A had been approximately equivalent for the RF and MP diets, the eggs derived from the RF groups had much higher vitamin A concentrations $(9.2 \mathrm{IU} / \mathrm{g})$ than the MP groups $(1.6 \mathrm{IU} / \mathrm{g})$ at the initial spawning stage for both groups. The SDP group, which had only about $1 / 5$ of the supply of vitamin A in the broodstock diet, had roughly equivalent concentrations of vitamin $\mathrm{A}$ in their eggs $(1.8 \mathrm{IU} / \mathrm{g})$ to those of the MP group. The high concentrations of vitamin $\mathrm{A}$ in the RF diet group are not likely to be explained by conversion of carotenoids, as this group had by far the lowest supply of total carotenoids in the broodstock diet among the 3 groups. Furthermore, the MP and SDP groups had vastly different carotenoid concentrations fed to their broodstocks and yet achieved similar concentrations of vitamin A in their eggs. Carotenoid concentrations in the eggs of the 3 groups followed a similar pattern to that of vitamin A. That is, even though the RF diet had the lowest total carotenoids supplied to the broodstock, the eggs had the highest concentrations of carotenoids $(28 \mathrm{mg} / 100 \mathrm{~g})$. Furthermore, even though they had quite different supplies of carotenoids in the broodstock diet, the MP and SDP groups had similar carotenoid concentrations in eggs $(\sim 5 \mathrm{mg} / 100 \mathrm{~g})$. The authors suggested that the high concentrations of carotenoids in the RF group relative to the other 2 groups was probably a consequence of the higher lipid content of these eggs (30\% versus 20 to $22 \%$ in the other two diet groups). Each of the groups did, however, have vastly different carotenoid compositions. The RF group diet carotenoids consisted of about $75 \% \beta$ carotene and $25 \%$ of an unknown carotenoid, but had almost exclusively lutein in the eggs. The MP group received almost exclusively $\beta$-carotene and this was reflected in nearly $100 \%$ of the same pigment accounting for carotenoids in the eggs. The proportion of $\beta$-carotene dropped off in the middle $(70 \%)$ and later $(54 \%)$ spawned eggs, with zeaxanthin and lutein making up the bulk of the rest of the carotenoids. In the SDP diet group, the eggs contained zeaxanthin $(62 \%)$ and lutein $(36 \%)$ in relatively consistent proportions from the intial to late spawning stages. The appearance of zeaxanthin and lutein in the eggs of the MP and SDP groups may reflect the conversion of astaxanthin, supplied in the diets of these fish, as reported by Miki et al. (1985).

To further evaluate the importance of carotenoids in larval development, eggs produced in the initial spawn of both the MP and SDP group were kept without being fed and sampled every two days until they all had died. Carotenoids were measured in these subsamples. The authors determined that lipids were utilised more effectively during the starvation period in the SDP group than in the MP group, and attribute this to the high content of carotenoids in the SDP larvae. Tunaxanthin appeared in the 2-day-old larvae of both the MP and SDP groups and was reflected in the decreasing concentrations of both lutein and zeaxanthin. Both Miki 
et al. (1985) and Fujita et al. (1983) have reported that these carotenoids can be converted to tunaxanthin. Overall, the authors report that the quality of eggs was highest in the SDP group and they attributed this higher quality to the greater mean content of carotenoid pigments in the eggs of this group (10 $\mathrm{mg} / 100 \mathrm{~g}$ in the SDP group versus 5 in the MP group). It should be noted, however, that the form of the carotenoid was important, as the SDP group had mostly lutein and zeaxanthin compared with mostly $\beta$-carotene for the MP group. Finally, they showed that vitamin $\mathrm{A}$ and $\mathrm{E}$ concentrations increased in the larvae from day 0 to until day 6 . For vitamin A this may reflect conversion from provitamin A carotenoids, but for vitamin $\mathrm{E}$ the increase must have reflected a concentration of the vitamin in steadily declining weight of the larval fish since these fish were not fed and fish cannot synthesise vitamin $\mathrm{E}$.

Similar to the evidence already presented for vitamin $\mathrm{E}$, carotenoid pigments may play a role in reducing contaminant induced damage in developing fish embryos. Petterrson and Lignell (1996) and Borjeson et al. (1996) both showed that carotenoid pigment concentrations were lower in Baltic salmon that developed M74, a characteristic mortality syndrome since attributed to low thiamine levels, than in sac fry that did not develop the syndrome. In similar studies, we failed to show any relationships between Early Mortality Syndrome (EMS, which is similar to M74 in also being corrected by thiamine treatment), and initial carotenoid content of lake trout (Salvelinus namaycush) eggs. Furthermore, the loss of carotenoids and retinoids during development in the fry from the EMS-affected batches of eggs was not significantly different to that in egg lots that did not develop EMS (Palace, 1998b).

\section{SUMMARY AND CONCLUSIONS}

It would seem that there is strong evidence to support a link between increased vitamin E content of fish eggs and increased reproductive fitness. This link, however, is not as well developed nor understood for vitamin A and carotenoids. Compounding our difficulty in understanding the importance of vitamin concentrations in the eggs of fishes are the small number of studies that have also considered the importance of overall reproductive strategy. The ability of maternal nutrition to affect egg quality and early development is, of course, dependent on the reproductive strategy of the fish in question. Continuous spawners with short vitellogenic cycles, including gilthead seabream (Sparus aurata), are more immediately affected by dietary changes than are annual spawners with long vitellogenic cycles (Fernández-Palacios et al., 1997). In the latter case, egg quality is determined by mobilisation of nutrients from longer term muscle storage sites (Izquierdo et al., 2001). Other factors related to the environment in which eggs incubate would also be expected to alter the requirements for vitamins in eggs. For example, it may also be that oxidation is a more important factor in species with larger eggs containing more yolk, and therefore more PUFA. More dependence on yolk reserves for early development and longer endogenous feeding stages would require more vitamin $\mathrm{E}$ and $\mathrm{A}$. Increased temperatures and rates of basal metabolism should also be considered, as should rates of embryonic development.

\section{ACKNOWLEDGEMENTS}

The authors wish to acknowledge the excellent research assistance of Danielle Godard. J. Werner was supported by an Experimental Lakes area Graduate Fellowship and a University of Manitoba Fellowship.

\section{REFERENCES}

Aas, G.H., B. Bjerkeng, T. Storebakken and B. Ruyter. - 1999. Blood appearance, metabolic transformation and plasma transport proteins of ${ }^{14} \mathrm{C}$ astaxanthins in Atlantic salmon (Salmo salar). Fish. Physiol. Biochem., 21: 325-334.

Ando, S., T. Takeyama, M. Hatano and K. Zama. - 1985. Carotenoid-carrying lipoproteins in the serum of chum salmon (Oncorhynchus keta) associated with migration. Agric. Biol. Chem., 49: 2185-2187.

Aruoma, O.I., H. Kaur and B. Halliwell. - 1991. Oxygen free radicals and human diseases. J. Roy. Soc. Health., 111: 172-177.

Baker, R.T.M. and S.J. Davies. - 1996. Oxidative nutritional stress associated with feeding rancid oils to African catfish, Clarias gariepinus (Burchell) and the protective role of a-tocopherol. Aquacult. Res., 27: 795-803.

Borjeson, H., L. Forlin, and L. Norrgren. - 1996. Investigation of antioxidants and prooxidants in salmon affected by M74 syndrome: report of the second workshop on reproduction disturbances in fish. Swedish Environmental Protection Agency Report, 4534. P.95-96.

Burton, G.W. and K.U. Ingold. - 1984. b-carotene: an unusual type of lipid antioxidant. Science., 224: 569-573.

Chen, H., M.J. Namkung and M.R. Juchau. - 1995. Biotransformation of all-trans-retinol and all-trans-retinal to all-trans-retinoic acid in rat conceptual homogenates. Biochem. Pharmacol., 50: 1257-1264.

Christiansen, R., Ø . Lie and O.J. Torrissen. - 1995. Growth and sur- 
vival of Atlantic salmon, Salmo salar L., fed different dietary levels of astaxanthin. Aquaculture Nutrition, 1: 189-198.

Ciarcia, G., M. Paolucci, G. Guerriero, G. Cozzolino and P. Abrescia.-2000. Determination of vitamin E in eggs and during the larval development of the sea bass, Dicentrarchus labrax, by high performance liquid chromatography. BioFactors., 11: 19-21

Cowey, C.B., J.G. Bell, D. Knox, A. Fraser, and A. Youngson. 1985. Lipids and antioxidant systems in developing eggs of salmon (Salmo salar). Lipids., 20: 567-572.

Craik, J.C.A. -1985. Egg quality and egg pigment content in salmonid fishes. Aquaculture., 47: 61-68.

D’Aquino, M., C. Dunster and R.L. Wilson. - 1989. Vitamin A and glutathione mediated free radical damage: competing reactions with polyunsaturated fatty acids and vitamin C. Biochem. Biophys. Res. Commun., 161: 1199-1203.

Das, N.P. - 1989. Effect of vitamin A and its analogs on nonenzymatic lipid peroxidation in rat brain mitochondrion. $J$. Nerurochem., 52: 585-588.

Deshpande, S.S., U.S. Deshpande and D.K. Salunke. - 1996. Nutritional and health aspects of food antioxidants. In: D.L. Madhavi, S.S. Deshpande and D.K. Salunkhe (eds.) Food antioxidants. technical, toxicological and health perspectives, pp.361-470. Marcel Dekker Publishers, New York, NY.

Deufel, J. - 1965. Pigmentierungsversuche mit canthaxanthin bei regenbogenforellen. Arch. Fischereiwiss., 16: 125-132.

Dimascio, P., M.E. Murphy and H. Sies. - 1991. Antioxidant defense systems: the role of carotenoids, tocopherols and thiols. Am. J. Clin. Nutr., 53: 194S-200S.

Draper, H.H. - 1980. Nutrient interrelationships. In: L.J. Machlin (ed.), Vitamin E. handbook of vitamins. 2nd edition. pp. 272288. Marcel Dekker New York, NY.

Duester, G. - 1996. Involvement of alcohol dehydrogenase, short chain dehydrogenase/reductase, aldehyde dehydrogeanse, and cytochrome $\mathrm{p} 450$ in the control of retinoid signaling by activation of retinoic acid synthesis. Biochemistry, 35: 12221-12227.

Eskelinen, P. - 1989. Effects of different diets on egg production and egg quality of Atlantic salmon Salmo . salar L.. Aquaculture, 79: 275-281.

Fernández-Palacios, H., M.S. Izquierdo, M. Gonzalez, L. Robaina and A. Valencia. - 1998. Combined effect of dietary a-tocopherol and n-HUFA on egg quality of gilthead seabream (Sparus auratus) broodstock. Aquaculture., 161: 475-476.

Fernández-Palacios, H., M.S. Izquierdo, L. Robaina, A. Valencia, M. Salhi and D. Montero. - 1997. The effect of dietary protein and lipid from squid and fish meals on egg quality of broodstock for gilthead seabream (Sparus aurata). Aquaculture., 148: 233-246.

Fox, H.M. and G. Vevrs. - 1960. The nature of animal color. Sidgwick and Jackson Ltd., London U.K.

Fujita, T., M. Satake, S. Nikichi, M. Takeda, S. Shimeno, H. Kuwabara, W. Miki, K. Yamaguchi and S. Konusu. - 1983. Pigmentation of cultured yellowtail with krill oil. Nippon Suisan Gakkaishi., 49: 1595-1600.

Furuita, H., H. Tanaka, T. Yamamoto, M. Shiraishi and T. Takeuchi. - 2001. Effects of high dose of vitamin A on reproduction and egg quality of Japanese flounder Paralichthys olivaceus. Fish. Sci., 67: 606-613

Goswami, U.C. - 1988. Carotenoid free diet and its role in reproduction of freshwater fish. In: J.B.C. Findlay, D.J.C. Pappin, M. Brett,and P.F. Zagalsky (eds.) Carotenoids: Proceedings of the 8th International Symposium on the Carotenoids, pp.32. Plenum press, NY.

Gross, J. and P. Budowksi. - 1966. Conversion of carotenoids into vitamin A1 and A2 in two species of freshwater fish. Biochem. J., 101: 747-754.

Halliwell, B. - 1987. Oxidants and human disease; some new concepts. FASEB J., 1: 358-364.

Halliwell, B., J.M.C. Gutteridge. - 1990. The antioxidants of human extracellualr fluids. Arch. Biochem. Biophys., 280: 1-8.

Hamre, K., R. Waagboo, R.K. Berge and O. Lie. - 1997. Vitamins $\mathrm{C}$ and $\mathrm{E}$ interact in juvenile Atlantic salmon (Salmo salar, L.). Free Rad. Biol. Med., 22: 137-149.

Hamre, K., R.K. Bege and O. Lie. - 1998. Turnover of ?-, ?, and ? tocopherol and distribution in subcellular and lipoprotein fractions indicate presence of an hepatic tocopherol binding protein in Atlantic salmon (Salmo salar L.). Fish Physiol. Biochem.,
18: $1573-1586$

Harris, L.E. - 1984. Effects of a broodfish diet fortified with canthxanthin on female fecundity and egg color. Aquaculture, 43: 179-183.

Hata, M. and M. Hata. - 1971. Carotenoid pigments in goldfish (Carassius auratus). I. composition and distribution of carotenoids. Int. J. Biochem., 2: 11-19.

Hata, M., M. Hata and T. Onishi. - 1973. Conversion of ?-carotene and retinol 1 to retinol 2 in freshwater fish. Tohoku J. Agric. Res., 24: 197-204.

Hemre, G.I., A. Mangor-Jensen, G. Rosenlund and O. Lie. - 1994a. Organ distribution of vitamins A and E during broodstock phase of female turbot (Scopthalmus maximus). Fiskeridir. Skr. Ser. Ernauer., 6: 141-149.

Hemre, G.I., A. Mabgor-Jensen, and O. Lie. - 1994b. Broodstock nutrition in turbot (Scopthalmus maximus) effect of dietary vitamin E. Fiskeridir. Skr. Ser. Ernauer., 8: 21-29.

Hilton, J.W. - 1989) The interaction of vitamins, minerals and diet composition in the diet of fish. Aquaculture, 79: 223 -244.

Hubbs, C. and L. Stavenhagen. - 1958. Effects of maternal carotenoid deficiency on the viability of darter (Osteichthyes) offspring. Physiol. Zool., 31: 280-283.

Hung, S.S., T.W. Moon, J.W. Hilton and S.J. Slinger. - 1982 Uptake, transport and distribution of dl-alpha-tocopheryl acetate compared to d-alpha-tocopherol in rainbow trout (Salmo gairdneri). J. Nutr., 112: 1590-1599.

Irie T., and T, Seki. - 2002. Retinoid composition and retinal localisation in the eggs of teleost fishes. Comp. Biochem. Physiol., 131B: 209-219.

Izquierdo, M.S., H. Fernández-Palacios and A.G.J. Tacon. - 2001. Effect of broodstock nutrition on reproductive performance of fish. Aquaculture., 197: 25-42.

Kimunaki, T. and K. Sugii. - 1972. Addition of fat soluble vitamins to the feeding stuffs for parent rainbow trout with particular reference to the effect on the vitamin levels in eggs and fry. Bull. Tokai Reg. Fish. Res. Lab., 71: 133.

King, I.B. - 1985. Influence of vitamin $E$ in reproduction in rainbow trout (Salmo gairdneri). Ph.D. thesis, Univ.Washington.

Kitahra, T. - 1984. Behaviour of carotenoids in the chum salmon, Oncorhychus keta, during development. Bull. Jpn. Soc. Fish., 50: $531-536$

Kitihara, T. - 1983. Behaviour of carotenoids in the chum salmon (Oncorhynchus keta) during anadromous migration. Comp. Biochem. Physiol., 76B: 97-101.

Laevens, P., E. Lebegue, H. Jaunet, A. Brunel, P. Dhert and P. Sorgeloos. - 1999. Effect of dietary essential fatty acids and vitamins on egg quality in turbot broodstocks. Aquacult. Internat., 7: 225-240.

Lie, O., A. Mangor-Jensen and G.I. Hemre. - 1993. Broodstock nutrition in cod (Gadus morhua) effect of dietary fatty acids. Fiskeridir. Skr. Wer. Ernaer., 6: 11-19.

Lie, O., A. Sandvin and R. Waagbo. - 1994. Transport of alphatocopherol in Atlantic salmon (Salmo salar) during vitellogenesis. Fish Physiol. Biochem., 13: 241-247.

Liebler, D.C. - 1993. The role of metabolism in the antioxidant function of vitamin E. Crit. Rev. Toxicol., 23: 147-169.

Lubzens, E., L. Lissauer, B. Levavi-Sivan, J.-C. Avarre and M. Sammar. - 2003.Carotenoid and retinoid transport to fish oocytes and eggs: what is the role of retinol binding protein. Mol. Aspects Med., 24: 441-457.

Madden, M. - 2001. Vitamin A and the developing embryo. Postgrad. Med. J., 77: 489-491.

Means, A.L. and L.J. Gudas. - 1995. The roles of retinoids in vertebrate development. Ann. Rev. Biochem., 64: 201-233.

Miki, W., K. Yamaguchi, S. Konosu, T. Tanake, M. Satake, T. Fujita, H. Kuwabara, S. Shimeno and M. Takeda. - 1985. Origin of tunaxanthin in the integument of yellowtail (Seriola quinqueradiata). Comp. Biochem. Physiol., 80B: 195-201.

Morrison, J.K. and C.E. Smith. - 1981. The effects of dietary carotenoid supplementation on egg quality of brook trout. Information Leaflet \#19, Fish. Dev. Centre, Bozeman, MT 6pp.

Mourente, G., D.R. Tocher, E. Diaz, A. Grau and E. Pastor. - 1999. Relationships between antioxidants, antioxidant enzyme activities and lipid peroxidation products during early development in Dentex dentex eggs and larvae. Aquaculture, 179: 309-324.

Murayama, S. and M. Yanase. - 1961. The amounts of chemical constituents of eyed eggs of rainbow trout from various 
sources. Bull. Tokai Reg. Fish. Res. Lab. 31:311-316.

Ojima, F., H. Sakamoto, Y. Ishiguro and J. Terao. - 1993. Consumption of carotenoids in photosensistised oxizdation of human plasma and low-density lipoprotein. Free Rad. Biol. Med., 15: 377-384.

Olson, J.A. - 1989. Provitamin A function of carotenoids: the conversion of b-carotene into vitamin A. J. Nutr., 119: 105-108.

Omenn, G.S., G.E. Goodman, M.D. Thornquist, J. Balmes, M.R Cullen, A. Glass, J.P. Keough, F.L. Meyskens, B. Valanis, J.H. Williams, S. Barnhardt, S. Hammar. - 1996. Effects of a combination of beta carotene and vitamin A on lung cancer and cardiovascular disease. New Engl. J. Med., 334: 1150-1155.

Packer, L. - 1991. Protective role of vitamin E in biological systems. Am. J. Clin. Nutr., 53: 1050S-1055S.

Palace, V.P., K. Wautier, R.E. Evans, C.L. Baron, J. Werner, C.R. Ranson, J.F. Klaverkamp and K. Kidd.-2001b. Effects of 17-b estradiol exposure on metallothionein and fat soluble antioxidant vitamins in juvenile lake trout (Salvelinus namaycush). Bull. Environ. Contam. Toxicol., 66: 591-596.

Palace, V.P. and SB Brown. - 1994. HPLC determination of tocopherol, retinol, dehydroretinol and retinyl palmitate in tissues of lake char (Salvelinus namaycush) exposed to coplanar 3,3',4,4',5-pentachlorobiphenyl. Environ. Toxicol. Chem. 13: 473-476.

Palace, V.P., K.G. Wautier, R.E. Evans, P. Blanchfield, K. Mills, S. Chalanchuk, D. Godard, M.E. McMaster, G. Tetrault, L.E Peters, L. Vandenbyllaardt and K.A. Kidd. - 2006. Biochemical and histopathological effects of ethynylestradiol in pearl dace (Semotilus margarita) exposed to a synthetic estrogen in a whole lake experiment. Environ. Toxicol. Chem.25: 260-271.

Palace, V.P., N. Khaper, Q. Qin and P.K. Singal. - 1999. Antioxidant potentials of vitamin A and carotenoids and their relevance to heart disease. Free Rad. Biol. Med., 26: 746-761.

Palace, V.P., R.E. Evans, K. Wautier, C.L. Baron, J. Werner, J.F. Klaverkamp, K.A. Kidd and T.A. Dick. - 2001a. Altered metabolism of lipid soluble antioxidant vitamins in juvenile sturgeon exposed to waterborne ethynylestradiol. Environ. Toxicol. Chem., 20: 2370-2376.

Palace, V.P., S.B. Brown, C.L. Baron, J.D. Fitzsimons and J.F. Klaverkamp. - 1998a. Relationships between induction of the phase I enzyme system and oxidative stress: relevance for lake trout from Lake Ontario and early mortality syndrome of their offspring. Amer. Fish. Soc. Symp., 21: 146-153.

Palace, V.P., S.B. Brown, C.L. Baron, J. Fitzsimmons, B. Woodin, J.J. Stegeman and J.F. Klaverkamp. - 1998b. An evaluation of the relationships among oxidative stress, antioxidant vitamins and early mortality syndrome (EMS) of lake trout (Salvelinus namaycush) from Lake Ontario. Aquat. Toxicol., 43: 195-208.

Palozza, P. and N.I. Krinsky. - 1992. Antioxidant effects of carotenoids in vivo and in vitro: an overview. Meth. Enzymol. 213: 403-420

Pettersson, A. and A. Lignell. - 1996. Decreased astaxanthin levels in the Baltic salmon and the M74 syndrome. Swedish environmental protection agency report of the second workshop on reproduction disturbances in fish. \# 4534. Nov 20-23, Stockholm Sweden.

Plack, P.A., A.D. Woodhead and P.M.J. Woodhead. - 1961. Vitamin A compounds in the ovaries of cod, Gadus morhua L., from the arctic. J. Mar. Biol. Ass. UK., 41: 617-630.

Plack, P.A., S.K. Kon and J.H. Thompson. - 1959. Vitamin A1 aldehyde in the eggs of the herring (Clupea harengus) and other marine teleosts. Biochem. J., 71: 467-476.

Quantz, G. - 1980. The influence of carotenoid-enriched dry feed on the egg fertilisation of rainbow trout. Arch. Fischereiwiss., 31: $29-40$.

Rousseau, E.J., A.J. Davidson and B. Dunn. - 1992. Protection by ?-carotene and related compounds against oxygen-mediated cytotoxicity and genotoxicity : implications for carcinogenesis. Free Rad. Biol. Med., 13: 407-433.

Sammar, M., P.J. Babin, M. Durliat, I. Mieri, I. Zchori, A. Elizur and E. Lubzens. - 2001. Retinol binding protein in rainbow trout; molecular properties and mRNA expression in tissues. Gen. Comp. Endocrin., 123: 51-61.

Schiedt, K., F.J. Leuenberger, M. Vecchi and E. Glinz. - 1985. Absorption, retention and metabolic transformations of carotenodis in rainbow trout and chicken. Pure Appl. Chem., 57: 685-692.

Schiedt, K., Mayer H., Vecchi M., Glinz E., Storebakken T., 1988. Metabolism of carotenoids in salmonids. Part 2. distribution and absolute configuration of idoxanthin in various organs and tissues of one Atlantic salmon (Salmo salar, L.) fed with astaxanthin. Helv. Chim. Acta, 71: 881-886.

Serbinova, E., V. Kagan, D. Han and L. Packer. - 1991. Free radical recycling and intramembrane mobility in the antioxidant properties of alpha-tocopherol and alpha-tocotrienol. Free. Rad. Biol. Med., 10: 263-275.

Shnarevich, I.D. and E.Z.G. Sachnenko. - 1972. Influence of carotenoid content of eggs of brown and rainbow trout on development of young. Biol. Nauki (Moscow), 15: 20-23.

Sies, H. and W. Stahl. -1995 . Vitamins $E$ and $C$ and b-carotene and other carotenoids as antioxidants. Am. J. Clin. Nutr., 62: 1315S$1321 \mathrm{~S}$.

Steffens, W. and H. Karst. - 1965. Chemische zusammensetzung and vitaminA-gehlt von eirn und brut der regenbogenforelle (Salmo garidneri Rich.). Z. Fisch., 13: 163-169.

Steffens, W. and H. Karst. - 1972. Der einfluss einer karotinreichen pflanzlichen beifutterung auf den vitamin-A-gehalt von regenbogenforellenbrut (Salmo gairdneri Rich.). Arch. Tiernaehr., 22: 439-444.

Stevens, D.M. - 1949. Studies on animal carotenoids. II. carotenoids in the reproductive cycle of brown trout. J. Exp. Biol., 26: 295-303.

Takeuchi, M., S. Ishii, and T. Ogio. - 1981. Effect of dietary vitamin $\mathrm{E}$ on growth, vitamin $\mathrm{E}$ distrbution and mortalities of the fertilised eggs and fry in ayu (Plecoglossus altivelis). Bull. Tokai. Reg. Fish. Res. Lab., 104: 111.

Takeuchi, K. - 1960. The behaviour of carotenoid and distribution of xanthophores during development of medaka (Oryzias latipes). Embryologia, 5: 170-177.

Tesoriere, L., M. Ciaccio, A. Bongiorno, A. Riccio, A.M. Pintaudo and M.A. Livrea. - 1993. Antioxidant activity of all-trans retinol in homogeneous solution and phosphatidyl liposomes. Arch. Biochem. Biophys., 307: 217-223.

Tokuda, M., T. Yamaguchi, K. Wakui, T. Sato, M. Ito and M. Takeuchi. - 2000. Tocopherol affinity for serum lipoproteins of Japanese flounder Paralichthys olivaceus during the reproduction period. Fisheries Science., 66: 619-624.

Torrissen, O.J., and R, Christiansen. - 1995. Requirements for carotenoids in fish diets. J. Appl. Ichthyol., 11: 225-230.

Torrissen, O.J. - 1984. Pigmentation of salmonids- effect of carotenoids in eggs and start-feeding diet on survival and growth rate. Aquaculture, 43: 185-193.

Vassalo-Aguis, R., T. Watanabe, K. Mushiake, K. Kawano and S. Satoh. - 1998. Chemical components of eggs and yolksac larvae obtained from striped jack broodstock fed on a raw fish mix or dry pellets. Fisheries Sci., 64: 759-765.

Verakunpiriya, V., T. Watanabe, K. Mushiake, V. Kiron, S. Satoh and T. Takeuchi. - 1996. Effect of broodstock diets on the chemical components of milt and eggs produced by yellowtail. Fish. Sci., 62: 610-619.

Wang, X.D. - 1994. Review: absorption and metabolism of bcarotene. J. Am. Coll. Nutr., 13: 314-325.

Watanabe, T. - 1990. Effect of broodstock diets on reproduction of fish. Actes Colloq. IFREMER., 9: 542-543.

Watanabe, T. , T. Koizumi, H. Suzuki, S. Satoh, T. Takeuchi, N. Yoshida, T. Kitada and Y. Tsukashima. - 1985. Improved quality of red sea bream eggs by feeding broodstock on a diet containing cuttlefish meal or on raw krill shortly before spawning. Nippon Suisan Gakkaishi., 51: 1511-1521.

Received October 6, 2005. Accepted February 21, 2006.

Published online September 26, 2006. 
